\title{
Apple Cider Vinegar Potential as an Adjuvant Therapy Breakthrough against Antibiotic Resistant Bacteria
}

\author{
Rizaldy Wahyudinata Danupoyo ${ }^{1}$, John Nolan ${ }^{1}$, Audrey Rachel Wijaya ${ }^{\mathbf{1}}$, \\ Agatha Nadya Lianto ${ }^{1}$, Darryl Rex Zaffyr Hasan'
}

${ }^{1}$ Medical Student, Faculty of Medicine, Udayana University, Bali, Indonesia

Corresponding Author: Rizaldy Wahyudinata Danupoyo

DOI: https://doi.org/10.52403/ijrr.20220157

\begin{abstract}
Introduction: One of the medical emergencies worldwide is antibiotic resistance caused by the irrational use of antibiotics. This issue increases the mortality and morbidity rates and challenges in selecting the appropriate therapeutic regimen in bacterial infection cases. Solution inquiry is still being conducted, including the research and development of new antibiotics. However, there is still an imbalance between the pacing rate of new antibiotic discovery and the emergence of the antibiotic resistance problem, so that currently, there are plenty of studies on alternative therapies. Apple cider vinegar (ACV) is a fermented fruit product that has been shown to have antimicrobial effects.

Methods: This review article was composed by conducting a journal search with the keywords "antibiotic resistance", "apple cider vinegar", and "antimicrobial". Among 39 journals that have been reviewed, 30 were found to be suitable as references for this article review.

Results: ACV can be used as an option in adjuvant therapy for antibiotics in overcoming the problem of antibiotic resistance. ACV works by inhibiting the growth of bacteria, which can be done by eliminating the expression of several proteins and enzymes that are crucial in bacterial growth. ACV can also reduce proinflammatory cytokines, increase monocyte activity, and fight free radicals. In the meantime, $\mathrm{ACV}$ is easy to obtain at an affordable price. However, the lack of studies on the effects of $\mathrm{ACV}$ is still an obstacle to potentiating this adjuvant therapy.
\end{abstract}

Conclusions: ACV can be used as adjuvant therapy in overcoming the problem of antibiotic resistance. Further research is still needed to determine the exact mechanism and effectiveness of $\mathrm{ACV}$ in the problem of antibiotic resistance.

Keywords: antibiotic resistance, apple cider vinegar, antimicrobial

\section{INTRODUCTION}

Antibiotic is a Latin-derived word that consists of anti means fight, and bios mean living. Antibiotic is a specific substance produced either by bacteria or fungi, which in some certain amount concentration has the capacity to inhibit or be lethal to other microorganisms. Certain types of antibiotics included to broadspectrum group (actively against numerous species/types bacteria), and some others belong to narrow-spectrum (only active against specific species/types bacteria) ${ }^{1,2}$

Since their first discovery, antibiotics have been very useful for human beings. Nonetheless, with the increasing utilization of antibiotics, some problems come with it, such as the emerging of multiple-antibiotic resistance bacterial strain, leading to ineffective usage of antibiotics in treating infectious diseases., , $^{2,3}$ This issue increases patient mortality and morbidity caused by antibiotic-resistant bacterial infection. ${ }^{4}$ From newly released world health organization (WHO) 
information in 2018, research conducted by Global Antimicrobial Resistance Surveillance System (GLASS) among 500.000 people from 22 countries, it is found that the most resistant bacterial strain are Escherichia coli, Klebsiella pneumoniae, Staphylococcus aureus, etc. ${ }^{5}$ According to Center for Disease Control and Prevention (CDC) in 2019, annually in the United States of America approximately there are 2.8 million infection cases caused by antibiotic resistance strain with mortality rate up to 35.000 patients. ${ }^{6}$ The bacterial sensitivity pattern data from several hospitals in Indonesia shows there has been methicillin resistance towards Staphylococcus aureus (MRSA) with a proportion around $13-26 \%{ }^{7}$

Numerous researches have been conducted to find the solution for this problem. The search for new antibiotics is also being encouraged, but researchers still could not catch up with the high rate of occurrence of resistance. ${ }^{8}$ This phenomenon leads to the condition where the research community placed Complementary / alternative medicine (CAM) to be developed as one among other approaches to this problem. ${ }^{8}$

CAM is typically described as an adjuvant program in diagnosis, treatment, or prevention that complements the common conventional medical treatment. ${ }^{9}$ Currently, CAM continues to be developed around the world. The most popular and widely used CAM treatment in developed and developing countries is herbal, and Indonesia has 9.600 types of medicinal plants containing various active substances. ${ }^{10,11}$ Indonesians have been using herbal for health purposes since a very long time ago. Based on fundamental health research (Riset Kesehatan Dasar / RISKESDAS) conducted from 2010 to 2018 , it is found that $44.3 \%$ of Indonesians are using herbal medicine to preserve their health. A study in the USA shows the utilization of herbal medicine among adults is $38 \%$ (4 of 10 people) and in children is $12 \%$ (1 of 9 people). ${ }^{13}$ One of the seeded programs from the Indonesia Health Ministry in 2011 is included herbal medicine in primary health care services. ${ }^{14}$ The current issue for CAM is to integrate with primary care, which is defined as a set of holistic services to increase health status, prevent diseases, and support diagnostic, curative, rehabilitation, supportive, and palliative programs. A major issue arising from CAM integration with conventional medicine is the basis of data and still lacking from evidence-based medicine (EBM) perspective. Because most of the herbal medicine still does not have a promising scientific basis, proven from the number of scientific journals which researching herbal medicine scoop still not abundant also the valid data and published research article still not prominent now days. ${ }^{15}$

Some newly conducted research has found that apple cider vinegar (ACV) could be used as an adjuvant therapy modality against antibiotic resistance, considering ACV's antimicrobial property and supporting the immune system. ${ }^{16,17} \mathrm{ACV}$ ability to suppresses the essential enzyme for bacterial growth, make it able for this purpose. Furthermore, ACV can stimulate monocyte activity so that the immune system can increase the defense against bacteria. $^{16}$

In this article review, the writer intended to further explain the efficiency and therapy potency from $\mathrm{ACV}$ as an adjuvant modality in treating bacterial resistance.

\section{METHODS}

The writing methodology used is a literature review. Literature sources consist of relevant journals from search engines PubMed, Google Scholar, and Nature. The keywords used are "antibiotic resistance", "apple cider vinegar", and "antimicrobial". The inclusion criteria were all studies of the antimicrobial potential of apple cider vinegar. The exclusion criteria were literature published in the last ten years and literature other than English and Indonesian. 
Of the 39 journals reviewed, 30 were suitable as references for this literature. The collected information is recorded, analyzed for validity and reliability, and interpreted and compiled into a single scientific literature review.

\section{RESULTS AND DISCUSSION Apple cider vinegar}

Vinegar has been used since more than 10.000 years ago. Commonly vinegar is produced from raw ingredients containing sugar or starch, which undergo double fermentation to produce ethanol and turn to acetic acid. Traditional vinegar can be produced from grape, apple, coconut, rice, and potato extract. The medicinal properties of vinegar include antimicrobial, antioxidants, lowering blood pressure, reducing the effects of diabetes, preventing heart and blood vessel disease, and increasing stamina. ${ }^{18}$

ACV is one example of a plantbased product that can be used as a CAM component. ACV production involves acetic acid-producing bacteria, namely the Acetobacteriaceae family, obligate aerobic gram-negative bacteria. ${ }^{18}$ In the ancient Roman era, ACV was used as a refreshing drink, while other historic civilizations believed it could maintain health and slow down the aging process. The father of medicine, Hippocrates, also uses ACV for various medical purposes such as treating cough, fever and wound care. ${ }^{19}$

ACV contains various flavonoid contents such as gallic acid, catechins, epicatechin, chlorogenic acid, caffeic acid, and $\mathrm{p}$-Coumaric acid with a total polyphenol index of up to 400 to $1000 \mathrm{mg} / \mathrm{L}$ gallic acid equivalent (GAE) which is related to the mechanism of action of ACV as an antioxidant, protective function of the body against oxidative stress. ${ }^{18}$

Currently, ACV is widely used as an alternative medicine for treating patients with hypercholesterolemia and obesity. Research conducted in Iran by 2012 shows a significant depletion in cholesterol levels for patients who consume 30 milliliter $4 \% \mathrm{ACV}$ twice a day. ${ }^{20}$ Besides that, a research in 2014 found 30-milliliter daily consumption of ACV for obesity patients combined with a reduction of 250 kilocalories from daily calorie requirement, patient experience decrease in appetite, waist circumference, also decrease in total body weight, try glyceride plasma and increase in HDL-C. ${ }^{21}$

\section{Acetic acid antimicrobial activity}

Acetic acid is a weak organic acid compound produced from the ethanol fermentation process with the help of acetic acid-producing bacteria. $^{22,23}$ Generally, acetic acid concentration in vinegar is around 3-5\%. ${ }^{22}$ Acetic acid is a potent antiseptic that has been used in wound care procedures since the era of world war I in 1914..$^{22,24,25}$ A study conducted by Rysell et al. found 30 minutes compress with $3 \%$ acetic acid in treating burn injury successfully eradicate Proteus vulgaris, P. aeruginosa, A. baumanii, group A and B Bhaemolytic Streptococci, S. epidermidis, S. aureus, and Enterococcus faecalis from wound field. ${ }^{25}$

For now-days, U.S. Food and Drug Administration has allowed the application of $0.25 \%$ acetic acid for bladder irrigation and $2 \%$ acetic acid concentration to treat external otitis. Besides its usefulness in the medical field, acetic acid is commonly used as a natural preservative ingredient. Acetic acid is used as a food preserving and antimicrobial agent for beef, pork, and chicken either from the contamination from Salmonella or E. coli. ${ }^{26}$

In the case of handling antibiotic resistance bacteria, one of the antibacterial properties of acetic acid is the capacity of anti-biofilm, which interferes with the bacteria biofilm component. Based on research in 2015, the administration of $0.5 \%$ acetic acid successfully eradicated Pseudomonas aeruginosa, and $1.0 \%$ can eradicate S. aureus. ${ }^{22,25}$ The action mechanisms of acetic acid inhibit and eradicate the biofilm created by bacteria. 0.1 to $2.5 \%$ concentration of acetic acid already able to eradicate the previously constructed 
bacterial biofilm. On the other hand, the administration of acetic acid to antibioticresistant and non-antibiotic-resistant bacteria did not show any difference in the antibacterial activity of acetic acid. ${ }^{25}$

\section{Flavonoid content in apple cider vinegar}

ACV contains several flavonoids such as gallic acid, catechins, epicatechins, chlorogenic acid, caffeic acid, and pCoumaric acid. Gallic acid has an antimicrobial mechanism by inhibiting motility, adhesion, and biofilm formation. In addition, its compounds can also damage the integrity of the bacterial cell membrane, changing the charge and permeability of the bacterial membrane surface. ${ }^{27}$ Catechins and epicatechins have antioxidant potential by acting directly as reactive oxygen species (ROS) scavengers and indirectly by inducing antioxidant enzymes, inhibiting pro-oxidant enzymes, and suppressing stress-induced pathways. ${ }^{28}$ Chlorogenic acid can donate hydrogen atoms, reducing free radicals and inhibiting oxidation reactions. ${ }^{29}$ Different action mechanisms performed by p-Coumaric acid through its ability to prevent cellular response cascade and decrease the inflammatory mediator such as TNF- $\alpha$ and IL- $6 .{ }^{30}$

\section{Antibiotic resistance}

One of the major drug groups in the medical world is antibiotics. In addition to human health, antibiotics are also used in advancing the agriculture process. Antibiotics have been studied since 1800, and the first antibiotic, penicillin, was discovered in the early $1900 \mathrm{~s}^{31}$ The years 1930 to 1960 were the gilded age of the discovery and use of antibiotics, but this has decreased since the emergence of antibiotic resistance. The failure to discover and develop new antibiotics is one of the factors that cause antibiotic resistance in the world. Several other things that encourage antibiotic resistance are the excessive use of antibiotics in humans and animals, the sale of antibiotics freely, increased mobility of foreign tourists, and low levels of hygiene. ${ }^{32}$
The antibiotic misuse in humans is a major cause of antibiotic resistance in Indonesia. ${ }^{33}$ Antibiotic resistance is a global problem that is dynamic and evolving all the time. Antibiotic resistance in the United States has caused 2 million infections and 23.000 deaths a year. In addition, antibiotic resistance is detrimental to the economic field as much as 55 to 70 billion per year for treatment. ${ }^{31}$ According to the World Health Organization report, between 2002 to 2008 in Indonesia, the E. coli resistance towards third-generation cephalosporin respectively was $10 \%$ for cefotaxime and $13.8 \%$ for ceftriaxone. Not to mention the E. coli infection cases in Indonesia as much $17.3 \%$ are fluoroquinolone resistance. ${ }^{4}$ As long 2001-2002, a study focused on methicillinresistant Staphylococcus aureus (MRSA) in Indonesia found that among $24 \%$ of patients screened for MRSA, about $4.3 \%$ of them are infected with it. ${ }^{33}$

\section{Mechanism of construction and administration of apple cider vinegar Inoculation and administration of apple cider vinegar on bacteria}

Construction or pre-administering process of ACV can be started by using apples that are washed and treated under high pressure to separate the fruit from the juice. ${ }^{19}$ The squeezed apple juice is then placed in a container and covered with gauze for 20 days before being transferred to another container and allowed to stand for another 20 days. $^{16,19}$ More simplified basic material can be directly chosen from the sold ACV in the market, but it must be ensured that there is no additional preservative in the component. ${ }^{19}$ The ACV is then cultured directly together with bacteria with several different concentrations and dilutions of juice. ${ }^{16,17,19}$ Some of the bacteria that have been the experimental targets for the antimicrobial effect of ACV include: E. coli, S. aureus, C. albicans, Enterobacter kobei, and several other bacteria. ${ }^{16,19}$ Each bacterium was first cultured on each medium before being cultured with ACV on Mueller-Hinton 
agar. ${ }^{16,17,19,34}$ E. coli and S. aureus were cultured on a nutrient medium while $\mathrm{C}$. albicans was cultured on Sabourand's medium. ${ }^{16}$ All cultures were incubated at $37^{\circ} \mathrm{C}$ for 18 to 24 hours. Each microbe was smeared on a petri dish on Mueller-Hinton solid medium and added $100 \mu \mathrm{L}$ of $\mathrm{ACV}$ with various concentrations before being incubated at $37^{\circ} \mathrm{C}$ for 24 hours. ${ }^{16,19}$ Furthermore, the inhibition of bacterial growth will be observed using millimeters (mm). The effectiveness of ACV can also be seen in the levels of proinflammatory cytokines using flowcytometry. ${ }^{19}$

According to the infectious etiology, direct administration of ACV can be done in the form of liquid or tablet and as an adjuvant therapy modality of conventional antibiotics. From existing studies, it was found that the minimum inhibitory concentration (MIC) of tablets for E. coli bacteria was $62 \mu \mathrm{g} / \mathrm{ml}$ and $125 \mu \mathrm{g} / \mathrm{ml}$ for S. aureus. ${ }^{16}$

Research by Yagnik in 2018 showed that bacterial growth by administering ACV from Bragg $\mathbb{R}$ with various concentrations could inhibit bacterial growth. ${ }^{16}$ The concentration of ACV was given starting from the undiluted, $1: 2,1: 5$, up to $1: 1000$. It was found that the undiluted ACV concentration was the most significant in inhibiting the growth of bacteria. ${ }^{16,19}$

\section{Apple cider vinegar action mechanism against bacterial growth}

\section{Antimicrobial and anti-inflammatory} effects of apple cider vinegar

$\mathrm{ACV}$ is an adjuvant therapy that is proven to have antimicrobial and antifungal potency. ACV's antimicrobial potency can be seen by its ability to inhibit bacterial growth. ${ }^{19}$ The antimicrobial effect of ACV differs in different species of bacteria. ${ }^{16,17,19}$ $\mathrm{ACV}$ also can interfere with the growth of microbes, suppressing inflammatory cytokine and promoting phagocytosis response. ${ }^{16,35}$

Administration of $\mathrm{ACV}$ induces damage to the integrity, structure, and metabolism of proteins and cell nucleus material in microbes. This mechanism can occur because some of the $50 \mathrm{~s}$ and $30 \mathrm{~s}$ ribosomes dissociate so that the 50/30s ribosomal complex does not form. ${ }^{16}$ In addition, ACV can also increase the phagocytosis of monocytes through the toll receptor signaling pathway to the exposed microbes. ${ }^{16}$

E. coli requires several enzymes to support its growth and life, such as citrate synthase, isocitrate dehydrogenase, malate dehydrogenase, and methylaminotransferase. These enzymes play a role in gene regulation and intracellular carbon metabolism. ACV administration to E. coli caused those previously mentioned enzymes to diminish and disturb some cellular mechanisms in E. coli, such as the Krebs cycle, pentose-phosphate pathway, glycosylation cycle, and oxidative phosphorylation. ${ }^{16,17}$ Besides that, the absence of DNA binding protein, such as ribosome A inhibitor in E. coli, can promote the unprotective state towards this bacteria and disturb the bacterial growth process. ${ }^{38,39}$ Different mechanisms applied to S. aureus, in which ACV can cast out the expression of some protein like DnaK chaperone and prevent the splitting of ftsz protein. This results in the disturbance of the bacterial defense mechanism for heat, oxidative stress, antibiotic and disturbing the carotenoid production declining. ${ }^{16}$

Apart from how ACV can interfere with the bacterial development process, ACV can also stimulate immunity and increase host protection against oxidative stress due to several active substances such as acetic acid and flavonoids. This is also supported by studies that state the success of ACV in suppressing levels of proinflammatory cytokines and increasing antioxidant levels in the body. ${ }^{18,39}$ Studies of the effect of ACV on bacteria have now gone through the in vitro stage. In general, it can be said that ACV can be a complementary modality that has antimicrobial effects and several other benefits on proinflammatory cytokine levels and host immunity. ${ }^{16}$ 
Rizaldy Wahyudinata Danupoyo et.al. Apple cider vinegar potential as an adjuvant therapy breakthrough against antibiotic resistant bacteria.

\section{Strengths and weaknesses}

Antimicrobial properties of ACV can significantly suppress and inhibit the growth progress of various species of bacteria, suppress cytokine proinflammation, and increase phagocytosis capability. Also, the active compound from $\mathrm{ACV}$ can increase the protective response from the immune system. Other valuable benefits of ACV are decreasing cholesterol levels and increasing protective properties against oxidative stress damage for the erythrocyte, kidney, and liver. ${ }^{40} \mathrm{ACV}$ is typically an easily obtained herbal product at an affordable price.

Although accompanied by many promising advantages in the mechanism against various types of bacterial resistance, several things need to be considered in the use of ACV, namely related to the level of acidity of ACV, which may affect gastric acidity. Several studies in the future also need to be developed further regarding the level of safety and toxicity of ACV products in their use against bacterial resistance.

\section{CONCLUSIONS}

The utilization of ACV can be concluded as an effective breakthrough in overcoming the problem of antibiotic resistance. This is based on several action mechanisms owned by ACV. ACV as an adjuvant therapy modality can be used to manage bacteria suspected of having developed resistance to current antibiotic therapy. The mechanism of ACV is related to the ability of ACV to inhibit bacterial growth by eliminating the expression of several proliferative enzymes and proteins that are crucial to the growth of some bacteria, such as E. coli and S. aureus. In addition, ACV can also reduce proinflammatory cytokines in the body and increase levels of antioxidants that can function as protection against oxidative stress. Some of these pathways can have a significant effect in overcoming the problem of bacterial resistance. The superiority of ACV can be measured using serum cytokines, leukocyte levels, and histopathological conditions. This advantage shows that ACV can be used as a complementary modality for future antibiotic resistance cases.

\section{Acknowledgement: None}

\section{Conflict of Interest: None}

\section{Source of Funding: None}

Ethical Approval: Not Applicable

\section{REFERENCES}

1. Zaman S, Hussain M, Nye R, Mehta V, Mamun K, Hossain N. A Review on Antibiotic Resistance: Alarm Bells are Ringing. Cureus. 2017.

2. Davies J, Davies D. Origins and Evolution of Antibiotic Resistance. Microbiology and Molecular Biology Reviews. 2010; 74(3): 417-433.

3. Liu B, Pop M. ARDB--Antibiotic Resistance Genes Database. Nucleic Acids Research. 2009;37:D443-D447.

4. World Health Organization Antimicrobial resistance: global report on surveillance 2014. Geneva, Switzerland: WHO; 2014.

5. World Health Organization. High levels of antibiotic resistance found worldwide, new data shows [Internet]. World Health Organization. 2019.

6. The biggest antibiotic-resistant threats in the U.S. [Internet]. Centers for Disease Control and Prevention. 2019.

7. Kakkar M, Chatterjee P, Chauhan AS, Grace D, Lindahl J, Beeche A et al. Antimicrobial resistance in South East Asia: time to ask the rightquestions. Glob Health Action. 2018;11(1):1483637.

8. Kok E, Jong M, Gravendeel B, Van Leeuwen W, Baars E. Resistance to Antibiotics and Antifungal Medicinal Products: Can Complementary and Alternative Medicine Help Solve the Problem in Common Infection Diseases? The Introduction of a Dutch Research Consortium. Evidence-Based Complementary and Alternative Medicine. 2015;2015:1-6.

9. Shirwaikar A, Govindarajan R, Rawat A. Integrating Complementary and Alternative 
Rizaldy Wahyudinata Danupoyo et.al. Apple cider vinegar potential as an adjuvant therapy breakthrough against antibiotic resistant bacteria.

Medicine with Primary Health Care. Hindawi. 2019.

10. "World Health Organization medicines Strategy 2002-2005,"

11. Salim Z, Ernawati Munadi E. Info Komoditi Tanaman Obat [Internet]. Bppp.kemendag.go.id. 2017.

12. Kemenkes Dorong Pengembangan Industri Obat Tradisional [Internet]. Kementrian Kesehatan Republik Indonesia. 2019.

13. The Use of Complementary and Alternative Medicine in the United States [Internet]. NCCIH. 2019.

14. Integrasi Pengobatan Tradisional dalam Sistem Kesehatan Nasional [Internet]. Kementrian Kesehatan Republik Indonesia. 2011.

15. Walach H. Complementary Medicine: A Serious Option as We Are Facing the Problem of Bacterial Antibiotic Resistance. Complementary Medicine Research. 2017;24(3):132-134.

16. Yagnik D, Serafim V, Shah A. Antimicrobial activity of apple cider vinegar against methicillin resistant Staphylococcus aureus and resistant E. coli. Journal of Bacteriology \& Parasitology. 2018;09.

17. Berrin; ALTUNER B. The antimicrobial activity of apple cider vinegar and grape vinegar, which are used as a traditional surface disinfectant for fruits and vegetables. Communications Faculty of Science University of Ankara Series C Biology Geological Engineering and Geophysical Engineering. 2018;27(1):1-10.

18. Budak Nilgun H, Aykin E, Seydim Atif C, Greene Annel K, Gusel-Seydim Zeynep B G. Functional Properties of Vinegar. Journal of Food Science. 2014;79(5):757-761.

19. Kalaba V, Marjanović Balaban Ž, Kalaba D. Antibacterial Activity of Domestic Apple Cider Vinegar. Agrofor. 2019;4(1):24-31.

20. Zahra Beheshti, Yiong Huak Chan, Hamid Sharif Nia, Fatemeh Hajihosseini, Rogheyeh Nazari, Mohammad shaabani, Mohammad Taghi Salehi Omran. Influence of apple cider vinegar on blood lipids. Life Sci J 2012;9(4):2431-2440.

21. Khezri S, Saidpour A, Hosseinzadeh N, Amiri Z. Beneficial effects of Apple Cider Vinegar on weight management, Visceral Adiposity Index and lipid profile in overweight or obese subjects receiving restricted calorie diet: A randomized clinical trial. Journal of Functional Foods. 2018; 43:95-102.

22. Bjarnsholt $T$, Alhede $M$, Jensen $P$, Nielsen A, Johansen H, Homøe P et al. Antibiofilm Properties of Acetic Acid. Advances in Wound Care. 2015;4(7):363-372.

23. Lynch K, Zannini E, Wilkinson S, Daenen L, Arendt E. Physiology of Acetic Acid Bacteria and Their Role in Vinegar and Fermented Beverages. Comprehensive Reviews in Food Science and Food Safety. 2019;18(3):587-625.

24. Fraise A, Wilkinson M, Bradley C, Oppenheim B, Moiemen N. The antibacterial activity and stability of acetic acid. Journal of Hospital Infection. 2013;84(4):329-331.

25. Halstead F, Rauf M, Moiemen N, Bamford A, Wearn C, Fraise A et al. The Antibacterial Activity of Acetic Acid against Biofilm-Producing Pathogens of Relevance to Burns Patients. PLOS ONE. 2015;10(9):e0136190.

26. Wali M K, Abed M M. Antibacterial activity of acetic acid against different types of bacteria causes. Journal of Food Technology Pres. 2019;3(1):1.

27. Kahkeshani, N., Farzaei, F., Fotouhi, M., Alavi, S., Bahramsoltani, R., Naseri, R., Momtaz, S., Abbasabadi, Z., Rahimi, R., Farzaei, M., Bishayee, A. Pharmacological effects of gallic acid in health and disease: A mechanistic review. Iranian Journal of Basic Medical Sciences, 2019; 22(3): 225237.

28. Bernatoniene J, Kopustinskiene D. The Role of Catechins in Cellular Responses to Oxidative Stress. Molecules. 2018;23(4): 965.

29. Liang N, Kitts D. Role of Chlorogenic Acids in Controlling Oxidative and Inflammatory Stress Conditions. Nutrients. 2015;8(1):16.

30. Zhu H, Liang Q, Xiong X, Wang Y, Zhang $Z$, Sun $M$ et al. Anti-Inflammatory Effects of p-Coumaric Acid, a Natural Compound of Oldenlandia diffusa, on Arthritis Model Rats. Evidence-Based Complementary and Alternative Medicine. 2018;2018:1-9.

31. Li B, Webster T. Bacteria antibiotic resistance: New challenges and opportunities for implant-associated orthopedic infections. Journal of Orthopaedic Research. 2017; 36(1): 22-32 
Rizaldy Wahyudinata Danupoyo et.al. Apple cider vinegar potential as an adjuvant therapy breakthrough against antibiotic resistant bacteria.

32. Aslam B, Wang W, Arshad M, Khurshid M, Muzammil S, Rasool M et al. Antibiotic resistance: a rundown of a global crisis. Infection and Drug Resistance. 2018; Volume 11:1645-1658.

33. Parathon H, Kuntaman K, Widiastoety T, Muliawan B, Karuniawati A, Qibtiyah M et al. Progress towards antimicrobial resistance containment and control in Indonesia. BMJ. 2017;:;3808.

34. AL-Salihi S, Mohammed jumaah I, Saleh S. Antibacterial Activity of Some Disinfectants and Detergents on some pathogenic bacteria. Journal of Pharmaceutical Sciences and Research. 2019;11(2):590-597.

35. Pourmozaffar S, Hajimoradloo A, Miandare H. Dietary effect of apple cider vinegar and propionic acid on immune related transcriptional responses and growth performance in white shrimp, Litopenaeus vannamei. Fish \& Shellfish Immunology. 2017;60:65-71.

36. Watson J, Baker T, Bell S, Gann A, Levine M, Losick R. Molecular biology of the gene. Boston: Pearson; 2014.

37. Saqib A. Antimicrobial Activity of Apple Cider Vinegar. Mapana - Journal of Sciences. 2017;16(2):11-15.
38. Calhoun L, Kwon Y. Structure, function and regulation of the DNA-binding protein Dps and its role in acid and oxidative stress resistance in Escherichia coli: a review. Journal of Applied Microbiology. 2010;110(2):375-386.

39. Kawashima S, Chen Z, Aoi Y, Patgiri A, Kobayashi Y, Nurse $\mathrm{P}$ et al. Potent, Reversible, and Specific Chemical Inhibitors of Eukaryotic Ribosome Biogenesis. Cell. 2016;167(2):512-524.e14.

40. Nazıroğlu M, Güler M, Özgül C, Saydam G, Küçükayaz M, Sözbir E. Apple Cider Vinegar Modulates Serum Lipid Profile, Erythrocyte, Kidney, and Liver Membrane Oxidative Stress in Ovariectomized Mice Fed High Cholesterol. The Journal of Membrane Biology. 2014;247(8):667-673.

How to cite this article: Rizaldy Wahyudinata Danupoyo, John Nolan, Audrey Rachel Wijaya. Apple cider vinegar potential as an adjuvant therapy breakthrough against antibiotic resistant bacteria. International Journal of Research and Review. 2022; 9(1): 502-509. DOI: https://doi. org/10.52403/ijrr.20220157 